\title{
LEGISLAÇÃO AMBIENTAL: UM HISTÓRICO DE DESAFIOS E CONQUISTAS PARA AS POLÍTICAS PÚBLICAS BRASILEIRAS.
}

\author{
Rodrigo Fraga Garvão ${ }^{1}$ \\ Simone Andrea Lima do Nascimento Baia ${ }^{2}$
}

\begin{abstract}
RESUMO
O presente artigo faz uma reflexão sobre as políticas públicas de proteção ao meio ambiente, em território brasileiro. Com uma abordagem histórica, apresenta os marcos normativos de proteção ao meio ambiente e suas conquistas, além de uma reflexão sobre a atual situação das discussões sobre meio ambiente na atualidade. Faz um recorte histórico do início do século XVII até o século XXI, abordando a ECO-92 e Rio 92, bem como, as Leis nº 9433/1997 e 9605/1998, premissas para a identificação dos avanços e conquistas normativas destinadas à proteção ao meio ambiente, no Brasil. Para esta pesquisa foram realizados os estudos no campo da legislação ambiental brasileira, dentre eles documentos oficiais, dentre eles, a constituição brasileira, decretos e leis.
\end{abstract}

Palavras-chave: Legislação. Ambiente. Território. Brasil.

\begin{abstract}
The present article makes a reflection on the public policies of protection to the environment, in Brazilian territory. With a historical approach, it presents the normative frameworks of protection to the environment and its achievements, as well as a reflection on the current situation of the discussions on the environment in the present time. It makes a historical cut from the beginning of the 17th century to the 21st century, addressing ECO-92 and Rio 92, as well as Laws 9433/1997 and 9605/1998, premises for the identification of advances and normative achievements for the protection of the environment in Brazil. For this research were carried out the studies in the field of Brazilian environmental legislation, among them official documents, among them the Brazilian constitution, decrees and laws.
\end{abstract}

Keywords: Law. Environment. Territory. Brazil.

\section{INTRODUÇÃO}

A legislação brasileira passou por longas e intermináveis discussões políticas para chegar ao que hoje chamamos de estado de direito à proteção ao meio ambiente. A busca por uma legislação ambiental parece ter sido uma "luta" incansável. Muitas ações em defesa da vida sustentável na terra fizeram com que cientistas, pesquisadores, políticos, artistas e sociedade civil se voltassem para reflexões de caráter efetivo, visando garantir a defesa de uma das maiores biodiversidades do mundo.

\footnotetext{
1 Mestre em Desenvolvimento e Meio Ambiente Urbano (UNAMA), professor assistente da Universidade Federal Rural da Amazônia.email:rodrigo.garvao@ufra.edu.br

${ }^{2}$ Mestra em Gestão Pública (NAEA_UFPA), Professora assistente da Universidade Federal Rural da Amazônia. E-mail: simone.baia@ufra.edu.br
} 
O Brasil se tornou palco de grandes debates em torno da temática da preservação ambiental, como foi o caso da Eco 92 e Rio 92, quando câmeras registraram o reencontro do cantor Sting ${ }^{3}$ e o líder caiapó Raoni. A imagem “das mãos dadas” se tornou emblemática em favor, principalmente da Amazônia e simbolizou a luta em favor dos direitos dos povos da floresta. O gesto tentou chamar atenção do mundo para que o estado brasileiro dessa maior atenção para a discussão em torno da usina de Belo Monte.

Mas sabe-se que essa luta, em favor de uma sociedade brasileira mais sustentável e consciente de sua responsabilidade para com o meio ambiente, possui uma história que surgiu no século XVII. Portanto, torna-se imprescindível rever neste artigo o passado de nossa história para entender nossos avanços ou retrocessos ao longo de todos esses anos no que diz respeito à legislação ambiental.

Fig. 01 - O reencontro de Sting e o líder caiapó Raoni

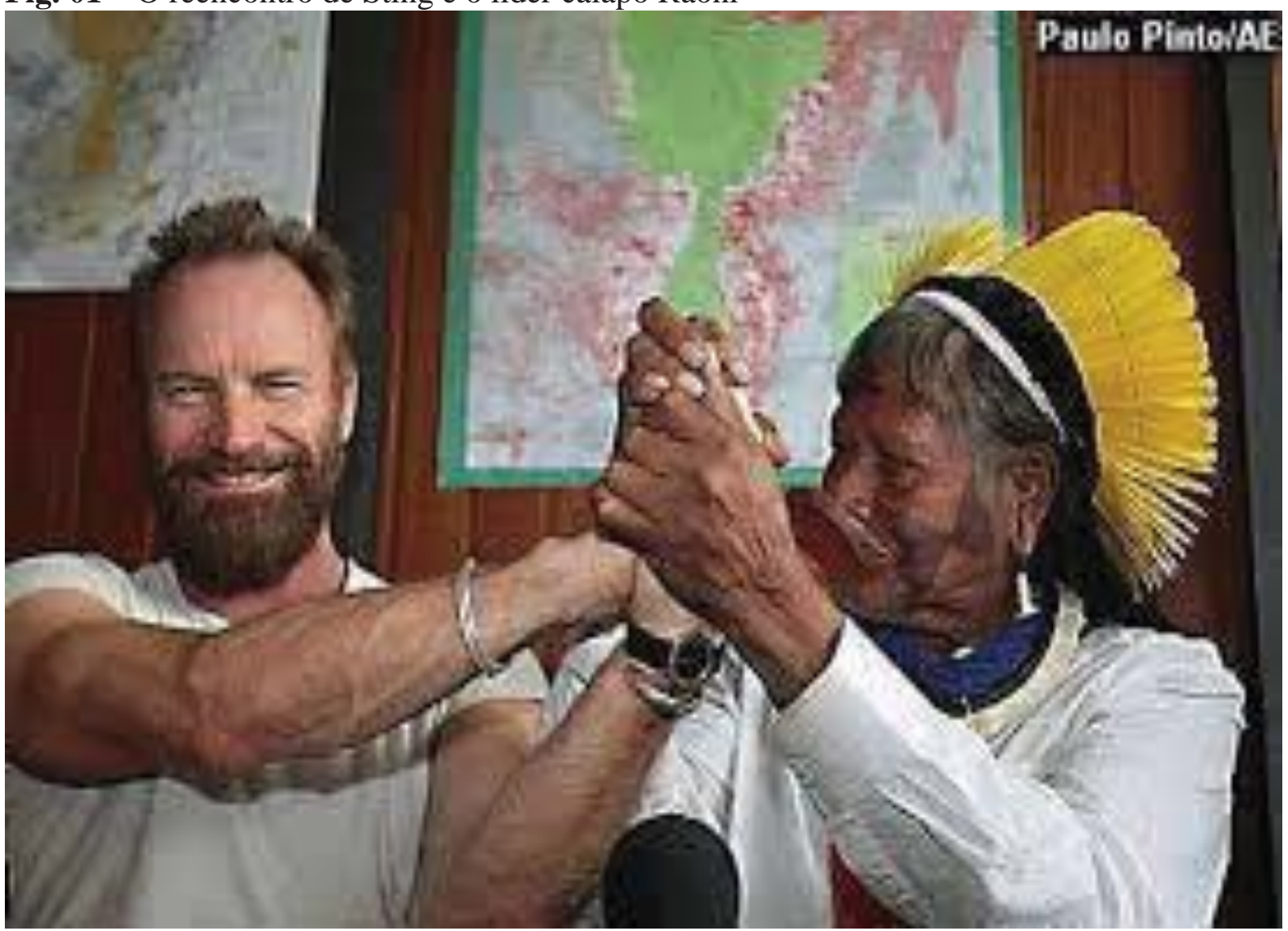

Fonte: Jornal - O Globo

\footnotetext{
${ }^{3}$ O cantor inglês viveu uma história interessante no Brasil, em especial na Amazônia, nos anos 1980. Sua primeira visita aconteceu em 1982, quando o cantor se apresentou em dois shows no Rio de Janeiro, ainda na época da sua banda The Police. Em 1987, quando já havia iniciado sua carreira solo, Sting retornou ao Brasil em 1987 para uma apresentação no estádio do Maracanã, e logo depois embarcou para a Amazônia, onde conheceu o cacique Raoni. O cantor passou meses na Amazônia, e se tornou um dos maiores defensores dos índios da região amazônica.
} 
Em 1605, foi aprovada a primeira lei de caráter ambiental no Brasil, voltada à proteção e preservação das florestas brasileiras, com destaque para o surgimento do Regimento Pau-Brasil, cujo objeto é a proteção das florestas nacionais. No ano de 1797, a criação da Carta Régia trouxe à tona a carência de proteção aos rios, nascentes e encostas, que se tornaram propriedades diretas da Coroa Portuguesa. Após dois anos, foi instituído o Regimento de Corte de Madeiras, cujo conteúdo impôs rígidas normas para a derrubada de árvores, principalmente as mais nobres, como o cedro e o mogno.

Quase um século depois do Regimento de Corte de Madeiras, em 1850, surgiu a expressão "madeira de lei" dada a sua proteção por meio de legislação, e foi, também, promulgada a lei $n^{\circ}$. 601/1850, referendada como a primeira Lei de Terras do Brasil, que disciplinou, a ocupação do solo e estabeleceu penalidades, no caso de sua utilização predatória. Anos depois, mais precisamente em 1861, o Rio de Janeiro, decretou as Florestas da Tijuca e das Paineiras, como área de preservação ambiental.

Em 1911, foi expedido o Decreto-Lei $n^{\circ} .8 .843$, que criou a primeira reserva florestal do Brasil, no antigo território pertencente ao estado do Acre; e, cinco anos depois, surgiu o Código Civil Brasileiro, que trouxe, em seu conteúdo, várias disposições protetivas ao meio ambiente, todavia, com uma visão patrimonialista e individualista acerca da fauna e da flora brasileira.

No ano de 1934, foram sancionados dois grandes projetos de lei para a preservação ambiental: o Código Florestal, por meio do Decreto de $\mathrm{n}^{\circ}$. 23.793; e o Código de Recursos Hídricos, também conhecido como Código das Águas. O primeiro impôs limites ao direito de propriedade e o segundo trouxe normas de conduta para a utilização da água; ambos deram origem ao que, décadas depois, se tornou a legislação ambiental brasileira. Dois anos mais tarde, foi criado o Código da Fauna, e, em seguida, fundou-se o Parque Nacional de Itatiaia uma grande unidade de conservação, área de proteção integral da natureza, localizada na Serra da Mantiqueira, entre os estados de Minas Gerais e Rio de Janeiro.

Somente em 1964, foi promulgada a Lei $\mathrm{n}^{\circ}$. 4.504, que dispõe sobre o Estatuto da Terra, em resposta às reivindicações de movimentos sociais que cobravam do governo federal mudanças estruturais na propriedade e no uso da terra no Brasil. Um ano depois, o Código Florestal Brasileiro foi ampliado, com a promulgação das leis 4.771 e 7.803 em 1965, trazendo um novo olhar para as políticas de proteção e conservação da flora, e, como ação efetiva, estabeleceu a proteção das áreas de preservação permanente.

Em 1967, foram editados os Códigos de Caça, de Pesca e de Mineração, além da lei de Proteção à Fauna (Lei $n^{\circ}$. 5.197), criminalizando, inclusive, a ação humana predatória ao 
meio ambiente, envolvendo desde a utilização das jazidas, florestas, caça, pesca e águas. Logo no ano seguinte, deu-se a realização da Conferência Mundial da Biosfera. Em 1972, ocorreu, na Suécia, a Conferência das Nações Unidas sobre o Meio Ambiente Humano (United Nations Conference on the Human Envirionment), mundialmente conhecida como Conferência de Estocolmo.

A questão da poluição passou a ter mais destaque a partir de 1975, em virtude da intensificação do controle sobre a poluição provocada por atividades industriais no Brasil. Por meio do Decreto-Lei $\mathrm{n}^{\circ}$. 1.413, de 1975, obrigou que as empresas adotassem medidas de proteção ao meio ambiente. E, em caso de danos, estão obrigadas a promover a reparação, por meio de ações corretivas. Dois anos depois, foi promulgada a Lei $n^{\circ} .6 .453$ de 1977, que instituiu a responsabilidade civil em caso de danos provenientes de atividades nucleares.

Em 1981, foi editada a lei $\mathrm{n}^{\circ}$. 6.938, que estabeleceu a Política Nacional de Meio Ambiente, tendo o meio ambiente como objeto específico de proteção. Seguindo o mesmo rumo, a lei $n^{\circ}$. 7.347, de 1985, disciplina a ação civil pública como instrumento processual específico para a Defesa do Meio Ambiente.

Somente com a promulgação da Constituição de 1988, o Brasil passou a ter mudanças significativas no cenário do meio ambiente, pois, pela primeira vez, foi destinado um capítulo específico para esta questão, com um conteúdo atual e moderno, impondo ao poder público e à sociedade em geral, conforme seu artigo 225, o dever de defender e preservar o meio ambiente para as gerações presentes e futuras, garantindo-lhes o direito de usufruí-las da melhor forma possível.

No ano de 1991, promulgou-se a Lei $n^{\circ} .8 .171$, e o Brasil passou a dispor de uma Lei de Política Agrícola. Assim como a Constituição de 1988, ela também trouxe um capítulo específico dedicado à proteção de meio ambiente, em que se apresentavam exigências principalmente para os ruralistas, pois os obrigava a recompor sua propriedade com reserva florestal obrigatória. No ano seguinte, houve a criação do Ministério de Meio Ambiente, além de ocorrer a Conferência Mundial das Nações Unidas sobre o Meio Ambiente e realizar-se a Eco 92, no Rio de Janeiro.

Em 1997, foi instituído o Sistema Nacional de Recursos Hídricos, por meio da Lei nº 9.433, e, no ano seguinte, foi publicada a Lei $\mathrm{n}^{\circ}$. 9.605, a qual dispõe sobre os crimes ambientais, em que são previstas sanções penais e administrativas para comportamentos danosos ao meio ambiente.

No final dos anos 90, mais precisamente em 1999, foi criada a Política Nacional de Educação Ambiental (Lei n ${ }^{\circ}$ 9.795), destinada a assegurar, no âmbito educativo, a integração 
da sustentabilidade à questão ambiental, social, ética, cultural, econômica, espacial e política para o desenvolvimento do país, buscando melhorar a qualidade de vida para toda a população brasileira, por meio do envolvimento e da participação social no tocante à proteção e conservação ambiental e à manutenção da natureza.

Em 2000, foi dado um dos mais importantes passos em direção ao Plano de Conservação, com a promulgação da Lei $\mathrm{n}^{\circ}$ 9.985, que institui o Sistema Nacional de Unidades de Conservação, prevendo mecanismos para a defesa dos ecossistemas naturais e de preservação dos recursos naturais neles contidos. No ano seguinte, foi sancionado o Estatuto das Cidades, através da Lei $n^{\circ}$. 10.257, de 2001, que dotou o ente municipal de mecanismos visando possibilitar que o seu desenvolvimento não viesse a acontecer em detrimento do meio ambiente. Ainda nesse mesmo ano, foi estabelecido o código de cores para diferentes tipos de resíduos, o qual passou a ser adotado na identificação de coletores e transportadores, conforme a Resolução $\mathrm{n}^{\circ}$. 275, de 25 de Abril de 2001 editada pelo Conselho Nacional de Meio Ambiente (Conama). Em 2002, ocorreu a Cúpula Mundial sobre Desenvolvimento Sustentável (Earth Summit 2002), também conhecida como Rio+10, em Johanesburgo, na África do Sul.

As discussões em torno do Meio Ambiente continuaram e novos avanços foram feitos na administração pública, como o Decreto $n^{\circ}$. 5.940, de 25 de outubro de 2006, que delega à administração pública a responsabilidade pela separação dos resíduos recicláveis descartados e pelo seu destino.

O ano de 2010 foi de grandes conquistas para a preservação ambiental: o detalhamento sobre a Educação Ambiental (Resolução Conama n. 422/2010); a definição de critérios de Sustentabilidade Ambiental, quando se trata de aquisição de bens; a contratação de serviços ou obras para a Administração Pública - Ministério do Planejamento, Orçamento e Gestão (Instrução Normativa $\mathrm{n}^{\circ}$. 01, de 19 de janeiro de 2010); por fim, a aprovação da Lei $\mathrm{n}^{\text {o }}$. 12.305, que criou a Política Nacional de Resíduos.

A discussão envolvendo a legislação ambiental teve seu último e mais significativo progresso com o novo Código Florestal Brasileiro, Lei n ${ }^{\circ}$ 12.651, em maio de 2012, quando no mês seguinte foi realizada a Conferência das Nações Unidas, que trouxe como matriz de discussões o desenvolvimento sustentável na Rio+20, no Rio de Janeiro em junho do mesmo ano. 
Fig.2- Abertura da conferência das nações unidas em junho de 2012

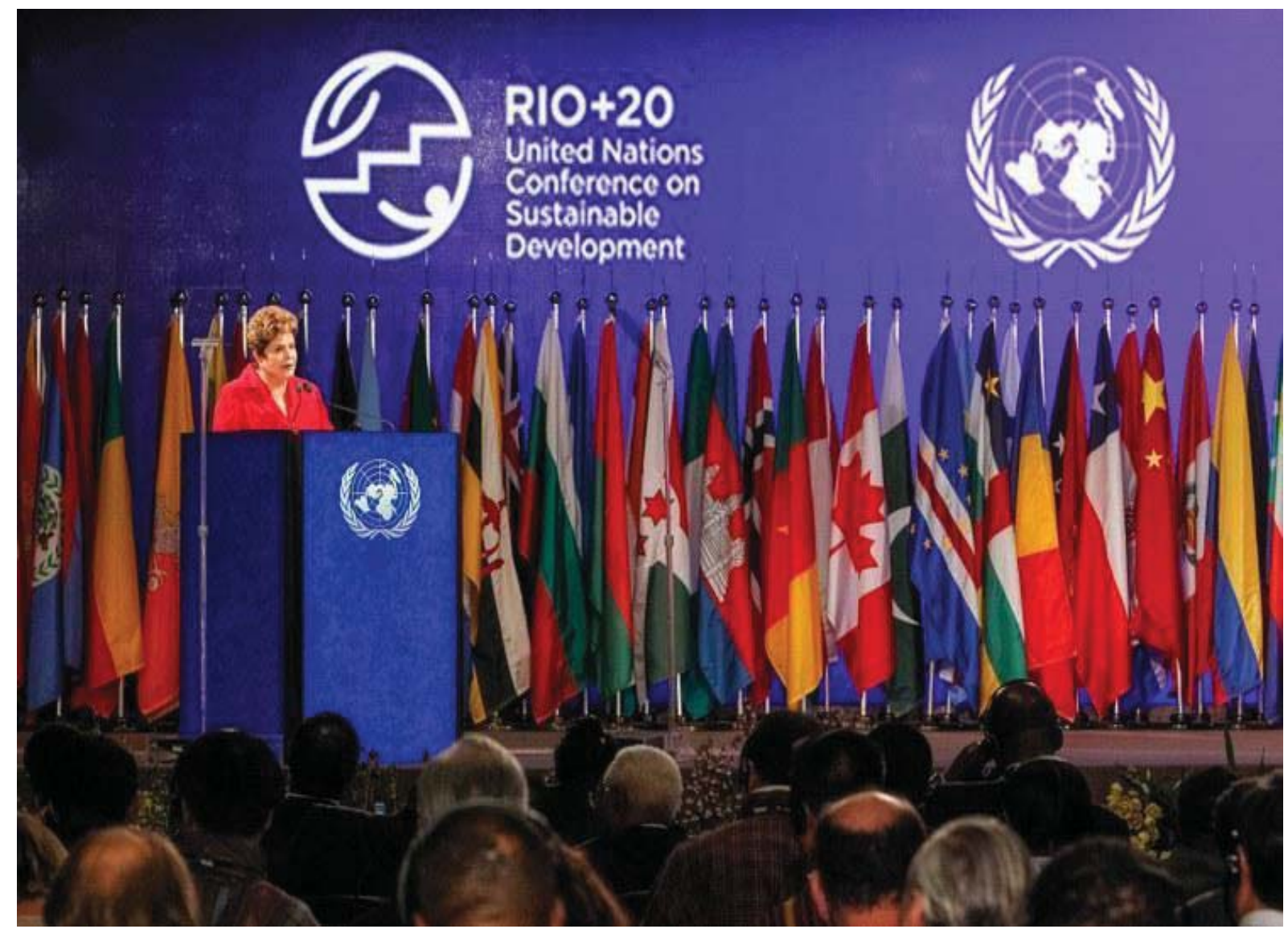

Fonte: Site oficial do planalto do governo

Ainda há muito o que se falar, discutir, refletir quando a ordem do dia é a preservação ambiental no Brasil. Mas já podemos considerar que o país passou por uma grande evolução no que diz respeito ao assunto, e, entre os grandes responsáveis por isso, figuram a comunidade científica, os ambientalistas e a sociedade em geral.

Em especial, nos últimos anos, o Brasil vem intensificando seus projetos ambientais em favor da redução de poluentes e realizando acordos internacionais que tratam do comprometimento com a proteção do meio ambiente. Portanto, percebe-se a extrema validade da participação do país nas conferências que desenvolvem discussões amplas em torno da questão ambiental, pois faz-se, ainda, notória a gravidade dos efeitos negativos ocasionados pela intervenção humana sobre o meio ambiente. 


\section{DIREITO AMBIENTAL: A BUSCA POR UM AMBIENTE ECOLOGICAMENTE EQUILIBRADO}

Segundo o Ministério do Meio Ambiente, no que concerne ao Direito Ambiental, foi dada importância ao tema, antes mesmo da Constituição Federal de 1988, exemplificando o Código Florestal pertencente à Lei no . 4.771/65 e à Lei de Fauna (Lei no. 5197/67). Entretanto, como foi ressaltado anteriormente, só foi dedicado um capítulo exclusivo ao Meio Ambiente a partir do artigo 225, da Constituição Federal: "Todos têm direito ao meio ambiente ecologicamente equilibrado, bem de uso comum do povo e essencial à sadia qualidade de vida, impondo-se ao poder público e à coletividade o poder de difundi-la e preservá-la para a presente e as futuras gerações."

Os anos 80 foram marcados por uma Política Nacional do Meio Ambiente no Brasil. Criou-se, inclusive, o Sistema Nacional do Meio Ambiente (Sisnama - Lei nº. 6938/81, modificado posteriormente pela Lei $\mathrm{n}^{\circ}$. 7804/89), que descreve os órgãos superior, central, executor, deliberativo/normativo, seccional e local e quais são as suas funções ligadas a esta política.

No ano de 1998, o Congresso Nacional aprovou a Lei nº. 9605, também chamada de Lei de Crimes Ambientais, que foi modificada e regulamentada pelo Decreto $n^{\circ}$. 3179/99, este posteriormente revogado pelo decreto $n^{\circ}$. 6514, de 2008. Essa Lei prevê, em seu art. $3^{\circ}$, penalidades nas três esferas - administrativa, civil e penal -, tanto para autoria ou coautoria em condutas lesivas ao meio ambiente, chegando a responsabilizar até pessoas jurídicas.

A referida Lei atendeu, até certo ponto, às expectativas da Carta da Terra e da Agenda 21, aprovadas durante a ECO-92, no Rio de Janeiro, onde os países signatários se comprometeram a criar leis para a responsabilização por males que sejam causados ao meio ambiente e para a compensação às vítimas da poluição. Mas a Lei ainda é palco de polêmicas: no governo federal, recebeu dez vetos e ainda apresenta muitas lacunas. Sua aprovação foi um avanço político e cultural para a proteção ao meio ambiente pelo fato de nomear crimes ecológicos com as repreensões legais.

Em 1997, surgiu outra lei em prol da defesa e proteção do meio ambiente: a Lei $n^{\circ}$. 9433/97, que estabeleceu uma Política Nacional para os Recursos Hídricos. O art. $2^{\text {o da }}$ referida lei elucida, a contento, os objetivos a que ela se propõe:

Art. $2^{\circ}$ São objetivos da Política Nacional de Recursos Hídricos: I - Assegurar à atual e futuras gerações a necessária disponibilidade de água, em padrões de qualidade adequados aos respectivos usos; 
II - A utilização racional e integrada dos recursos hídricos, incluindo o transporte aquaviário, com vistas ao desenvolvimento sustentável;

III - a prevenção e a defesa contra eventos hidrológicos críticos de origem natural ou decorrentes do uso inadequado dos recursos naturais.

Ainda com relação à Lei 9433/97, é relevante mencionar à criação do Sistema Nacional de Recursos Hídricos (SINGREH). Três anos mais tarde à promulgação desta norma, foi editada a Lei $n^{\circ}$. 9985, de 2000, que institui o Sistema Nacional de Unidade de Conservação (SNUC), o qual caracteriza as categorias de Unidade de Conservação, estabelecendo critérios e normas para a criação, implantação, conservação e gestão das mesmas, com o intuito de modernizar e estabelecer ações do poder público federal para a conservação da biodiversidade brasileira. Dentre suas diretrizes o artigo $5 .^{\circ}$ assegura, nos casos possíveis, a sustentabilidade econômica das unidades de conservação; orientando que o processo de criação e gestão de tais unidades ocorram de forma integrada com as políticas de administração das terras e águas circundantes, considerando as condições e necessidades sociais e econômicas locais; ou seja, deve-se considerar as condições e necessidades das populações locais no desenvolvimento e adaptação de métodos e técnicas de uso sustentável dos recursos naturais; buscando proteger grandes áreas por meio de um conjunto integrado de unidades de conservação de diferentes categorias, próximas ou contíguas, e suas respectivas zonas de amortecimento e corredores ecológicos, integrando as diferentes atividades de preservação da natureza, uso sustentável dos recursos naturais e restauração e recuperação dos ecossistemas.

\section{CONSIDERAÇÕES FINAIS}

A Legislação brasileira ambiental vem apresentando avanços desde o Brasil colônia. A criação da Carta Régia em 1797, trouxe à tona a carência de medidas de proteção aos rios, nascentes e às encostas brasileiras, que se tornaram propriedades diretas da Coroa Portuguesa, representaram os primeiros passos de uma discussão que formatou a atual política de proteção ao meio ambiente brasileiro.

Dentre tantos avanços na legislação brasileira, chama-se atenção para a criação da Lei $\mathrm{n}^{\text {o. }}$ 9605/98, chamada de Lei de Crimes Ambientais, posteriormente modificada e regulamentada pelo Decreto $n^{\circ}$. 3179/99, este revogado pelo decreto $n^{\circ}$. 6514/08. A lei prevê penalidades nas esferas, administrativa, civil e penal, para as ações ou omissões nocivas ao meio ambiente. Ao aliar imposições rígidas para o crime ambiental, este normativo, foi ao 
encontro da pretensão daqueles que clamavam por medidas punitivas mais rigorosas, para inibir ações prejudiciais ao meio ambiente, no Brasil, passando a criminalizar agressões de toda natureza, ao meio ambiente. Neste sentido, considera-se positiva a criação deste instituto, visto que trouxe inovações no que diz respeito a imposição de sanções penais, ao instituir como crime, as ações humanas lesivas ao meio ambiente.

Hoje percebe-se que há uma legislação que compreende o meio ambiente brasileiro como um sistema de espaços territoriais a partir de unidades de conservação - Sistema Nacional de Unidades de Conservação da Natureza (SNUC). A proposta do governo federal brasileiro em construir uma ação de proteção ao meio ambiente com foco no desenvolvimento sustentável fez do país um dos principais Estados do mundo preocupados em combater a exploração inadequada do meio ambiente.

Hoje, o Brasil constrói uma legislação baseada em um sistema de gestão ambiental sustentável que objetiva preservar e melhorar a vida natural e humana no território brasileiro. Nesse contexto, a criação do SNUC, assume posição estratégica no contexto da legislação brasileira, pois une a atividade econômica a ideia da sustentabilidade em busca do equilíbrio homem/natureza. Mas ainda há muito a avançar no quesito preservação e sustentabilidade no Brasil, pois há necessidade de se construir uma sociedade em que esses temas possam fazer parte principalmente do cotidiano das pessoas, que vá da família à escola, do estado à sociedade e dos sujeitos ao espaço.

\section{REFERÊNCIAS}

BRASIL. Constituição (1988). Constituição da República Federativa do Brasil. Senado Federal, Brasília, DF. Disponível em: http://www.planalto.gov.br/ccivil_03/Constituicao/Constituiçao_Compilado.htm .Acesso em: 17/04/2016.

Decreto $\mathbf{n}^{\circ}$ 23.793, de 23 de janeiro de 1934. Aprova o Código florestal que com este baixa. Senado Federal, Brasília, DF. Disponível em: <http://www.planalto.gov.br/ccivil_03/decreto/1930-1949/D23793.htm >. Acesso em: 09 ago. 2016.

Lei $\mathbf{n}^{\circ}$ 4.771, de 15 de setembro de 1965. Institui o novo código florestal. Senado Federal, Brasília, DF. Disponível em: <http://www.planalto.gov.br/ccivil_03/Leis/L4771compilado.htm>.Acesso em: 1 maio 2016.

. Lei ${ }^{\circ}$ 6.902, de 27 de abril de 1981. Dispõe sobre a criação de Estações Ecológicas, Áreas de Proteção Ambiental e dá outras providências. Senado Federal, Brasília, DF. 
Disponível em: <http://www.planalto.gov.br/ccivil_03/Leis/L6902.htm>. Acesso em: 08 maio 2016.

Lei $\mathbf{n}^{\circ} \mathbf{. 9 3 8}$, de 31 de agosto de 1981. Dispõe sobre a Política Nacional do Meio Ambiente, seus fins e mecanismos de formulação e aplicação, e dá outras providências. Senado Federal, Brasília, DF. Disponível em: <http://www.planalto.gov.br/ccivil_03/Leis/L6938compilada.htm>. Acesso em: 05. ago. 2016.

Lei $\mathbf{n}^{\circ}$ 7.735, de 22 de fevereiro de 1989. Dispõe sobre a extinção de órgão e de entidade autárquica, cria o Instituto Brasileiro do Meio Ambiente e dos Recursos Naturais Renováveis e dá outras providências. Senado Federal, Brasília, DF. Disponível em: <http://www.planalto.gov.br/ccivil_03/Leis/L7735.htm>. Acesso em 17/05/2016.

Lei $\mathbf{n}^{\circ}$ 9.605/98. Dispõe sobre as sanções penais e administrativas derivadas de condutas e atividades lesivas ao meio ambiente, e dá outras providências. Senado Federal, Brasília, DF. Disponível em: <http://www.planalto.gov.br/ccivil_03/Leis/L9605.htm>. Acesso em: 08 abr. 2016.

Lei 9.985/2000. Regulamenta o art. 225, $\S 1^{\circ}$, incisos I, II, III e VII da Constituição Federal, institui o Sistema Nacional de Unidades de Conservação da Natureza e dá outras providências. Senado Federal, Brasília, DF. Disponível em: Acesso em: 04 jul 2016.

BOTELHO, Cássia Regina Ossipe Martins. Org. Preservação ambiental. Um discurso de todos da Eco 92 à Rio + 20. Brasília: Câmara dos deputados. Edições câmara, 2012. 